\title{
Potencialidades e Desafios do Curso de Licenciatura em Computação a Distância da UFSM/UAB
}

\author{
Sidnei Renato Silveira ${ }^{1}$, Adriana Soares Pereira ${ }^{2}$, Cristiano Bertolini ${ }^{3}$, Fábio José \\ Parreira $^{4}$, Guilherme Bernardino da Cunha ${ }^{5}$
}

Departamento de Tecnologia da Informação - Universidade Federal de Santa Maria Campus Frederico Westphalen - RS (UFSM/FW)

Caixa Postal 54 - CEP 98400-000 - Frederico Westphalen - RS - Brazil

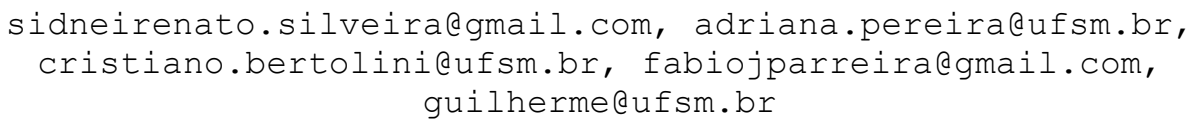

Resumo. Este artigo apresenta as potencialidades e desafios do Curso de Licenciatura em Computação, ofertado na modalidade a distância pela Universidade Federal de Santa Maria (UFSM) - Campus Frederico Westphalen - RS, no âmbito da Universidade Aberta do Brasil (UAB). O Curso é ofertado, atualmente, em 5 polos da UAB no Estado do RS, contando com 61 alunos matriculados. As potencialidades e desafios apresentados são resultantes das discussões originadas nos workshops de qualificação dos docentes e tutores do curso, realizados anualmente.

Palavras-Chave: Curso de Licenciatura em Computação, Educação a Distância, Potencialidades e Desafios

\begin{abstract}
This paper presents the strengths and challenges of Computer science graduation course, in the form of distance education by Federal University of Santa Maria (UFSM) - Campus Frederico Westphalen - RS, in the context of Brazil Open University (UAB). The course is happening at 5 $U A B$ poles in RS State, with more than 61 students enrolled. The presented strengths and challenges result from teachers and tutors workshops, which occur annually.
\end{abstract}

Keywords: Computer Science Graduation Course, Distance Education, Strengths and Challenges

\footnotetext{
${ }^{1}$ Professor Adjunto do Departamento de Tecnologia da Informação da UFSM/FW. Doutor em Ciência da Computação pela UFRGS

2 Professora Associada do Departamento de Tecnologia da Informação da UFSM/FW. Doutora em Ciência da Computação pela UFRGS

${ }^{3}$ Professor Adjunto do Departamento de Tecnologia da Informação da UFSM/FW. Doutor em Ciência da Computação pela UFPE

${ }^{4}$ Professor Associado Departamento de Tecnologia da Informação da UFSM/FW. Doutor em Engenharia Elétrica pela UFU

5 Professor Adjunto do Departamento de Tecnologia da Informação da UFSM/FW. Doutor em Engenharia Elétrica pela UFU
} 
VII Congresso Brasileiro de Informática na Educação (CBIE 2018)

Anais dos Workshops do VII Congresso Brasileiro de Informática na Educação (WCBIE 2018)

\section{Introdução}

O Curso de Licenciatura em Computação da Universidade Federal de Santa Maria (UFSM) - Campus Frederico Westphalen - RS é ofertado desde o ano de 2017, na modalidade a distância, no âmbito da Universidade Aberta do Brasil (UAB). O curso foi criado por docentes do Departamento de Tecnologia da Informação no ano de 2013 e submetido ao edital da CAPES no início do ano de 2015 (Edital 075/2014) (CAPES, 2014). Conforme o edital, o curso deveria ter iniciado em 2016 mas, devido a problemas orçamentários, o mesmo iniciou no $1^{\circ}$ semestre de 2017.

Foram ofertadas 125 vagas, sendo 25 em cada um dos polos da UAB, todos no Estado do Rio Grande do Sul: Cruz Alta, Palmeira das Missões, Sarandi, Seberi e Três Passos. O curso iniciou suas atividades acadêmicas em março de 2017, contanto com 109 alunos matriculado, 8 tutores (sendo 5 tutores presenciais -1 em cada polo de oferta e 3 tutores virtuais), além de 6 docentes formadores, que assumiram as disciplinas relativas ao $1^{\text {o }}$ semestre do currículo. O currículo do curso ${ }^{6}$, bem como o Projeto Pedagógico completo, podem ser encontrados no site da UFSM - Campus Frederico Westphalen - RS (UFSM, 2018).

Neste contexto, este artigo apresenta um breve histórico do Curso de Licenciatura em Computação a distância da UFSM-FW/UAB, bem como discute suas potencialidades e desafios.

\section{O Curso de Licenciatura em Computação a Distância da UFSM/UAB}

O Projeto Pedagógico do Curso de Licenciatura em Computação na modalidade a distância foi elaborado no ano de 2013, sendo submetido aos órgãos competentes da UFSM para sua devida aprovação. O projeto foi submetido ao edital 075/2014 da CAPES, no início do ano de 2015, sendo aprovado para oferta em 5 polos da UAB no Estado do RS, já citados anteriormente. Pelo cronograma do edital, o curso deveria iniciar suas atividades em 2016 mas, devido a problemas orçamentários, o mesmo teve início no $1^{\circ}$ semestre de 2017.

Antes do curso ser iniciado, tendo-se em vista a publicação da Resolução 2/2015 do Conselho Nacional de Educação (MEC, 2015), foi necessário adequar o Projeto Pedagógico do Curso, para atender, entre outros aspectos, às seguintes normas da resolução: 1) estruturação do currículo em núcleos: formação geral, aprofundamento e diversificação de estudos e estudos integradores; 2) 400 horas destinadas ao Estágio Supervisionado e 3) inclusão de disciplinas voltadas à Educação Especial e Diversidades Étnico-Racial, de Gênero, Sexual e Religiosa. O Estágio Supervisionado é desenvolvido nos $5^{\circ}, 6^{\circ}, 7^{\circ}$ e $8^{\circ}$ semestres respectivamente, nas disciplinas de Estágio Supervisionado I (90h), II (90h), III (105h) e IV (120h). Os temas envolvendo a diversidade são discutidos de forma transversal e, também, na disciplina de Tópicos Especiais em Diversidade Cultural.

O Curso possui 3.320 horas, assim distribuídas: 3030 horas de disciplinas obrigatórias (incluindo as 405 horas destinadas ao Estágio Supervisionado), 90 horas de

\footnotetext{
6 O Projeto Pedagógico do Curso está disponível no link $<$ http://w3.ufsm.br/frederico/index.php/curso/educacao-a-distancia-ead?layout=edit\&id=1962>
} 
VII Congresso Brasileiro de Informática na Educação (CBIE 2018)

Anais dos Workshops do VII Congresso Brasileiro de Informática na Educação (WCBIE 2018)

Disciplinas Complementares de Graduação (Optativas) e 200 horas de Atividades Complementares.

Ainda em 2016, antes de iniciar as atividades acadêmicas do curso, foram elaborados os e-books das disciplinas relativas ao $1^{\mathrm{o}}$ semestre do currículo (UFSM, 2018), sendo eles: Metodologia da Aprendizagem em EaD, Lógica Matemática, Aplicativos Computacionais aplicados à Educação, Informática Básica, Fundamentos Filosóficos e Sociológicos da Educação e Laboratório de Montagem e Manutenção. Os e-books que já possuem o International Standard Book Number (ISBN), estão disponíveis para download, gratuitamente, no site do Núcleo de Tecnologia Educacional (NTE) da UFSM, órgão que presta apoio às atividades dos cursos ofertados no âmbito da UAB na UFSM (NTE, 2018). Em 2016 também foram solicitadas a aquisição de equipamentos (incluindo kits Arduíno e kits de Robótica Educacional) e de livros para suprir a biblioteca de acordo com o Projeto Pedagógico do Curso. Entretanto, por problemas orçamentários, os equipamentos e livros ainda não foram adquiridos.

Em março de 2017 foram iniciadas as atividades acadêmicas do curso. A coordenação do curso, juntamente com um docente, visitou todos os 5 polos e realizou uma aula inaugural, apresentando as principais características do curso, bem como a forma de funcionamento. Na UFSM, os cursos ofertados no âmbito da UAB utilizam o Ambiente Virtual de Aprendizagem (AVA) Moodle. O NTE é o órgão responsável pelo gerenciamento do AVA, realizando o cadastro das disciplinas, professores formadores, tutores e alunos. Todos os tutores (presenciais e/ou virtuais) devem, obrigatoriamente, realizar a formação para uso do AVA, ministrada pelo NTE.

Ainda em 2017, foi constituído o Colegiado do Curso de Licenciatura em Computação (composto por 5 docentes), além de ser realizado o I Workshop de Qualificação dos Docentes e Tutores. O workshop foi realizado no campus da UFSM de Frederico Westphalen - RS. Foram convidados a participar os docentes conteudistas (responsáveis pela elaboração dos e-books), formadores, tutores e coordenadores dos polos onde o curso é ofertado. Participaram, do I Workshop, 13 pessoas, sendo 8 docentes (formadores e/ou conteudistas), 1 bolsista da Secretaria do Curso, 2 tutores presenciais (Polos de Sarandi e Seberi), 1 coordenador de polo (Sarandi) e 1 tutor virtual. A $1^{\text {a }}$ edição do workshop teve, como temática, "Perspectivas do Curso de Licenciatura em Computação".

Em 2018 foi constituído o Núcleo Docente Estruturante (NDE). Além disso, foi realizada a I Jornada Acadêmica do Curso de Licenciatura em Computação e a $2^{\mathrm{a}}$ edição do Workshop de Qualificação dos Docentes e Tutores. A I Jornada Acadêmica foi realizada nos 5 polos de apoio presenciais da UAB onde o curso é ofertado. Em cada polo foi apresentada uma temática diferente, sendo: 1) Polo de Cruz Alta: Construção de Objetos de Aprendizagem com a Ferramenta Ardora, 2) Polo de Palmeira das Missões: Sala de Aula Invertida, 3) Polo de Sarandi: Programação em Python, 4) Polo de Seberi: Criptomoedas e 5) Polo de Três Passos: Construindo Jogo Educacionais Digitais com a Ferramenta Construct. Cada atividade foi ministrada por um docente integrante do Colegiado do Curso.

O II Workshop de Qualificação dos Docentes e Tutores contou com a participação de 21 pessoas, sendo 14 docentes, 1 bolsista da Secretaria do Curso, 1 discente, 1 tutor presencial (Polo de Sarandi), 2 coordenadores de polos (Polos de Sarandi e Três Passos) e 2 responsáveis pela área de Tecnologia da Informação (Polos 
VII Congresso Brasileiro de Informática na Educação (CBIE 2018)

Anais dos Workshops do VII Congresso Brasileiro de Informática na Educação (WCBIE 2018)

de Seberi e Três Passos). Neste workshop foram discutidas as potencialidades e os desafios do Curso de Licenciatura em Computação, além de uma discussão sobre Pensamento Computacional e a inclusão do ensino de Lógica de Programação na Educação Básica, de acordo com os estudos encaminhados pela Sociedade Brasileira de Computação (SBC).

A Figura 1 apresenta os dados de matrículas, desde o início do curso (2017/1) até o semestre atual de integralização ( $4^{\circ}$ semestre do curso - 2018/2).

\begin{tabular}{|c|c|c|c|c|}
\hline & $2017-1$ & $2017-2$ & $2018-1$ & $2018-2$ \\
\hline Cruz Alta & 20 & 15 & 13 & 12 \\
\hline Palmeira das Missões & 24 & 17 & 14 & 13 \\
\hline Sarandi & 24 & 20 & 15 & 12 \\
\hline Seberi & 19 & 16 & 15 & 11 \\
\hline Três Passos & 22 & 16 & 14 & 13 \\
\hline & 109 & 84 & 71 & 61 \\
\hline
\end{tabular}

Figura 1: Número de Alunos Matriculados (Fonte: Os autores, 2018)

Com relação ao índice de evasão, no Curso de Licenciatura em Computação tem-se, até o momento, um percentual de 55,96\%. A evasão nos demais cursos de Licenciatura ofertados na modalidade de EaD pela UFSM/UAB, segundo dados fornecidos pelo NTE/UFSM é de 44,93\%. Apesar do índice do Curso de Licenciatura em Computação ser maior do que o dos demais cursos, cabe destacar que a evasão em Cursos da área de Computação no Brasil, segundo Hoed (2017) é de 75\% até o final do curso e, no exterior, é de 50\%. A Figura 2 apresenta os dados da evasão, considerando as rematrículas realizadas semestralmente desde o início do curso. Atualmente, o curso conta com 61 alunos matriculados.

\begin{tabular}{|c|c|c|c|c|}
\hline & 2017-1 & 2017-2 & 2018-1 & 2018-2 \\
\hline Cruz Alta & 20 & $\begin{array}{c}15 \\
25 \%\end{array}$ & $\begin{array}{c}13 \\
13,33 \%\end{array}$ & $\begin{array}{c}12 \\
7,69 \%\end{array}$ \\
\hline Palmeira das Missões & 24 & $\begin{array}{c}17 \\
29,17 \%\end{array}$ & $\begin{array}{c}14 \\
17,65 \%\end{array}$ & $\begin{array}{c}13 \\
7,14 \%\end{array}$ \\
\hline Sarandi & 24 & $\begin{array}{c}20 \\
16,66 \%\end{array}$ & $\begin{array}{c}15 \\
25 \%\end{array}$ & $\begin{array}{c}12 \\
20 \%\end{array}$ \\
\hline Seberi & 19 & $\begin{array}{c}16 \\
15,79 \%\end{array}$ & $\begin{array}{c}15 \\
6,25 \%\end{array}$ & $\begin{array}{c}11 \\
26,66 \%\end{array}$ \\
\hline \multirow[t]{2}{*}{ Três Passos } & 22 & $\begin{array}{c}16 \\
27,27 \%\end{array}$ & $\begin{array}{c}14 \\
12,5 \%\end{array}$ & $\begin{array}{c}13 \\
7,14 \%\end{array}$ \\
\hline & 109 & $\begin{array}{c}84 \\
22,78 \%\end{array}$ & $\begin{array}{c}71 \\
14,95 \%\end{array}$ & $\begin{array}{c}61 \\
14,08 \%\end{array}$ \\
\hline
\end{tabular}

Figura 2: Número de Alunos Matriculados e Evasão (Fonte: Os autores, 2018) 
VII Congresso Brasileiro de Informática na Educação (CBIE 2018)

Anais dos Workshops do VII Congresso Brasileiro de Informática na Educação (WCBIE 2018)

\section{Potencialidades e Desafios do Curso de Licenciatura em Computação}

Durante a $2^{\mathrm{a}}$ edição do Workshop de Qualificação dos Docentes e Tutores, além das questões envolvendo o Pensamento Computacional, foram discutidas as potencialidades e desafios do Curso de Licenciatura em Computação. Entre as potencialidades do curso, destacam-se:

- produção de $e$-books, envolvendo docentes do Departamento de Tecnologia da Informação da UFSM-FW, além de docentes externos. Até o momento já foram produzidos 21 e-books, sendo que 7 já possuem o ISBN e estão disponíveis para download no site do NTE (NTE, 2018);

- processo de elaboração criterioso dos e-books: o processo de elaboração dos $e$ books envolve, além dos professores conteudistas, uma equipe multidisciplinar do NTE/UFSM, responsável pela revisão pedagógica, linguística e diagramação dos materiais. Os materiais devem ser construídos em linguagem conversacional, considerando a interatividade;

- avaliações presenciais agendadas: os alunos podem agendar as avaliações presenciais das disciplinas, nos polos de apoio presencial. Durante a semana de provas, os alunos podem escolher o dia (entre segunda-feira e sábado), para realizarem as avaliações;

- avaliação substitutiva: o Colegiado do Curso, visando ofertar uma possibilidade extra de avaliação, criou a avaliação substitutiva. Caso o aluno não possa comparecer no polo na semana das avaliações presenciais ou não atinja a média para aprovação (média 7, de acordo com o Regimento da UFSM), pode se submeter à avaliação substitutiva, que também é presencial e precisa ser agendada junto aos polos;

- identificação do perfil do ingressante: a Coordenação do Curso, por meio de um formulário do Google, fez o levantamento do perfil do ingressante. Por meio deste levantamento verificou-se, entre outros aspectos, que mais de $50 \%$ dos alunos atua na área de Educação. Além disso, muitos alunos já concluíram outros cursos de graduação em diferentes áreas (tais como História, Geografia, Pedagogia e Teologia) e já possuem cursos de Pós-Graduação Lato e/ou Stricto Sensu;

- premiação dos alunos destaque: o Colegiado do Curso aprovou um regulamento próprio em que, semestralmente, os 3 alunos com a maior média geral das disciplinas cursadas, são premiados com uma menção honrosa;

- estúdio para gravação de videoaulas em Frederico Westphalen - RS: o NTE, localizado no campus sede da UFSM (em Santa Maria - RS), possui uma estrutura própria para a gravação de videoaulas. Entretanto, os docentes do Curso de Licenciatura em Computação estão sediados no campus de Frederico Westphalen, que fica a mais de 300km de distância. Sendo assim, para evitar os custos com os deslocamentos até o campus sede, a UFSM-FW firmou um acordo de cooperação com o Instituto Federal Farroupilha (IFFar) - Campus Frederico Westphalen, para utilizar o estúdio de videoaulas lá existente. As videoaulas são gravadas com o apoio de um servidor técnico da área audiovisual e de uma docente do Curso de Licenciatura em Computação. Ambos possuem experiência nestas atividades; 
VII Congresso Brasileiro de Informática na Educação (CBIE 2018)

Anais dos Workshops do VII Congresso Brasileiro de Informática na Educação (WCBIE 2018)

- realização de workshops para qualificação dos docentes e tutores do curso (conforme mencionado na seção anterior);

- realização da I Jornada Acadêmica (já mencionada na seção anterior);

- disciplinas de Observação e Reflexão do Trabalho Escolar: o currículo do curso contempla duas disciplinas de Observação e Reflexão do Trabalho Escolar, no $3^{\circ}$ e $4^{\circ}$ semestres. A primeira disciplina foi realizada em 2018/1. Os alunos puderam desenvolver atividades em escolas das cidades onde residem, propiciando, entre outros aspectos: um momento de interação entre a UFSM e a comunidade; conhecimento da realidade das escolas e de como a Computação pode ser inserida neste ambiente, além da abertura de campos para os futuros estágios supervisionados que iniciarão no ano de 2019. Em 2018/1 foram desenvolvidas atividades de observação em 30 escolas, em 17 cidades onde residem os alunos do curso;

- participação dos alunos em monitorias: tendo-se em vista as dificuldades apresentadas por alguns alunos, no que diz respeito à lógica de programação, alunos com conhecimento de programação se disponibilizaram a atuar como monitores, após a Coordenação do Curso ter encaminhado uma mensagem pedindo apoio dos colegas. Sendo assim, 3 alunos atuaram como monitores nos últimos 2 semestres (2018-1 e 2017-2), nos polos de Cruz Alta, Palmeira das Missões e Sarandi;

- comunicação constante com os alunos: por meio de um grupo de e-mails criado no Google Groups (lic-computacao-ead-uabufsm@googlegroups.com) e de uma página do curso, criada no Facebook (https://www.facebook.com/Curso-deLicenciatura-em-Computacao-a-distancia-Ufsm-Uab-1286013834825160/), a Coordenação do curso divulga informações sobre o Curso de Licenciatura, sobre eventos na área de Tecnologia da Informação, oportunidades de estágios/empregos, entre outros. Além disso, foi criado o projeto Conhecendo o Curso de Licenciatura em Computação. Este projeto divulga informações sobre a UAB, a modalidade de EaD e o funcionamento dos cursos da UAB na UFSM. destacam-se:

Com relação aos desafios que se apresentam para a condução do curso, - os e-books não têm sido impressos: por falta de recursos, os $e$-books estão sendo disponibilizados somente na forma digital;

- de acordo com os parâmetros atuais de concessão de bolsas, o número de tutores é condicionado ao número de alunos matriculados (um tutor a cada 18 alunos). $\mathrm{O}$ curso iniciou com 8 tutores (5 presenciais e 3 virtuais). Atualmente possuímos tutores presenciais em apenas 2 polos (Palmeira das Missões e Sarandi) e 2 tutores virtuais, que precisam dar conta de todas as disciplinas ofertadas em cada semestre;

- também de acordo com os parâmetros atuais de concessão de bolsas da CAPES, não existe mais a figura de Coordenador de Tutoria. Sendo assim, a Coordenação do Curso precisa absorver esta atividade;

- os livros constantes no Projeto Pedagógico do Curso ainda não foram adquiridos. 
VII Congresso Brasileiro de Informática na Educação (CBIE 2018)

Anais dos Workshops do VII Congresso Brasileiro de Informática na Educação (WCBIE 2018)

Apesar das dificuldades orçamentárias da CAPES, verifica-se existem mais potencialidades do que desafios na condução do Curso de Licenciatura em Computação.

\section{Considerações Finais}

Apesar do índice de evasão do Curso de Licenciatura em Computação estar em nível mais elevado do que as demais licenciaturas ofertadas pela UFSM/UAB, o mesmo ainda encontra-se abaixo do limite da área de Computação, conforme trabalho apresentado por Hoed (2017). Verificou-se que a maior dificuldade dos alunos é com relação às disciplinas que envolvem o estudo de Lógica de Programação e Programação de Computadores, como também acontece em cursos presenciais da área de Computação (SOUZA et al., 2018). Os índices de evasão apresentados anteriormente envolvem, entre outros fatores, as dificuldades de aprendizagem nas disciplinas de Introdução a Algoritmos (ofertada no $2^{\circ}$ semestre do curso - 2017/2) e Linguagem de Programação I (ofertada no $3^{\circ}$ semestre do curso - 2018/1).

Entre os desafios que ainda podem ser destacados com relação ao Curso de Licenciatura em Computação está o de preparar os futuros Licenciados em Computação para atuarem na Educação Básica, no contexto do desenvolvimento do pensamento computacional e da inclusão do estudo de Lógica de Programação na Base Nacional Comum Curricular (GARLET et al., 2016).

Além das potencialidades já destacadas anteriormente, os docentes do Departamento de Tecnologia da Informação submeteram ao NTE duas novas propostas, para serem analisadas no edital 05/2018 da CAPES (CAPES, 2018). Uma das propostas é a oferta do Curso de Licenciatura em Computação em 5 novos polos, todos no Estado do RS: Cachoeira do Sul, Constantina, Jacuizinho, Tio Hugo e Três de Maio. A segunda proposta é um Curso de Especialização Lato Sensu em Docência em EaD, voltado para a qualificação de docentes que desejam atuar na modalidade de EaD. Este curso foi proposto para ser ofertado nos polos onde o Curso de Licenciatura em Computação é ofertado atualmente.

Estas propostas são alicerçadas na experiência que os docentes do Departamento de Tecnologia da Informação da UFSM-FW possuem nas áreas de Informática aplicada à Educação e de Educação a Distância.

\section{Referências}

CAPES, Coordenação de Aperfeiçoamento de Pessoal de Nível Superior. (2014). Edital 75/2014: Oferta de vagas em cursos superiores na modalidade a distância no âmbito do Sistema Universidade Aberta do Brasil. Brasília: CAPES. Disponível em: $<$ https://www.capes.gov.br/images/stories/download/editais/Edital-075-2014UAB.pdf $>$. Acesso em agosto, 2018.

CAPES, Coordenação de Aperfeiçoamento de Pessoal de Nível Superior. (2018). Edital 05/2018: Chamada para articulação de cursos superiores na modalidade EaD no âmbito do programa UAB. Disponível em: <http://www.capes.gov.br/editaisded/8771-edital-5-2018-chamada-para-articulacao-de-cursos-superiores-namodalidade-ead-no-ambito-do-programa-uab>. Acesso em setembro, 2018. 
VII Congresso Brasileiro de Informática na Educação (CBIE 2018)

Anais dos Workshops do VII Congresso Brasileiro de Informática na Educação (WCBIE 2018)

GARLET, D.; BIGOLIN, N. M.; SILVEIRA, S. R. (2016). Uma Proposta para o Ensino de Programação na Educação Básica. Frederico Westphalen: UFSM. Disponível em: <https://repositorio.ufsm.br/handle/1/12961>. Acesso em junho, 2018 .

HOED, R. M. (2017). Análise da Evasão em Cursos Superiores: o caso da evasão em cursos superiores da área de computação. Brasília: UnB. Mestrado Profissional em Computação Aplicada (Dissertação). Disponível em: <http://repositorio.unb.br/handle/10482/22575>. Acesso em março, 2018.

MEC, Ministério da Educação. (2015). Resolução 2/2015: Define as Diretrizes Curriculares Nacionais para a formação inicial em nível superior (cursos de licenciatura, cursos de formação pedagógica para graduados e cursos de segunda licenciatura) e para a formação continuada. Brasília: Conselho Nacional de Educação - CNE/Ministério da Educação - MEC. Disponível em: <http://w3.ufsm.br/frederico/images/res_cne_cp_002_03072015.pdf >. Acesso em setembro, 2018.

NTE, Núcleo de Tecnologia Educacional. (2018). Materiais Didáticos. Núcleo de Tecnologia Educacional. Santa Maria: NTE/UAB/UFSM. Disponível em: <https://nte.ufsm.br/noticias/14-como-usar-o-moodle/118-material-didatico>. Acesso em agosto, 2018.

SOUZA, N. G.; SILVEIRA, S. R.; PARREIRA, F. J. (2018). Proposta de uma Metodologia para Apoiar os Processos de Ensino e de Aprendizagem de Lógica de Programação na Modalidade de Educação a Distância. Revista ECCOM, v.9, n.18. Disponível em: <http://fatea.br/seer3/index.php/ECCOM/article/view/851/856>. Acesso em junho, 2018.

UFSM, Universidade Federal de Santa Maria. (2018). Projeto Pedagógico do Curso de Licenciatura em Computação a Distância. Frederico Westphalen: UFSM-FW/UAB. Disponível em: <http://w3.ufsm.br/frederico/index.php/curso/educacao-a-distanciaead?layout=edit\&id=1962>. Acesso em agosto, 2018. 